\title{
Research on Constructing Integrated Operation System of Public Sports Service in the Blue Economic Zone of Shandong Peninsula
}

\author{
Meixia $\mathrm{He}^{1, *}$ \\ ${ }^{1}$ Department of Sports, Shandong Technology and Business University, Yantai, Shandong 264005, China \\ *Corresponding author. Email: lwhmx129@163.com
}

\begin{abstract}
Using the methods of literature, investigation and interview, and combining with the strategic measures of the state to vigorously promote the construction of the Blue Economic Zone of Shandong Peninsula, this paper proposes the necessity and feasibility of the integration construction of public sports services in the Blue Economic Zone of Shandong Peninsula. Through the investigation and research on the current situation of the integration of public sports services in the Blue Economic Zone of Shandong Peninsula, the problems in the integration of the public sports services in the Blue Economic Zone of Shandong Peninsula are deeply analyzed. In view of the existing problems and the experience of integrated construction of public service in China and foreign countries, the overall concept and operation measures for the integrated construction of the public sports service system in the Blue Economic Zone of Shandong Peninsula were proposed.
\end{abstract}

Keywords: Shandong Peninsula, Blue Economic Zone, public sports service, integration

\section{INTRODUCTION}

In the 21 st century, the marine economy has become the new main growth point of China's economic development. The "Development Plan of Blue Economic Zone of Shandong Peninsula" has become the first national development plan officially approved by the State Council during the period of 12th Five-Year Plan. The construction of Blue Economic Zone of Shandong Peninsula has become a national development strategy. The development of sports industry is an important part of the coordinated development of economy and society in the Blue Economic Zone of Shandong Peninsula. Equalization of basic public services will be an important goal of social development and construction in the future, and sports public services are an important part of the public service system. Providing high-quality sports public service is an important measure to build a harmonious society and realize the Chinese dream of people's happy life. Seizing the strategic opportunity of Shandong to build a Blue Economic Zone and planning the integrated development pattern of the public sports service system in the Blue Economic Zone of Shandong Peninsula lay a theoretical foundation for improving the public sports service system of Shandong Province, and provide theoretical support and scientific basis for leadership decision-making.

\section{RESEARCH METHODS}

This paper adopts literature review method, widely looks up the relevant literature and materials in China and foreign countries, as well as the information about the development of public sports services in the relevant cities of Blue Economic Zone of Shandong Peninsula in recent years.

By means of telephone interview, field interview and questionnaire survey, Chinese experts and scholars, relevant leaders of relevant urban sports bureau of Blue Economic Zone of Shandong Peninsula, leaders of some individual associations and citizens of relevant cities of Blue Economic Zone of Shandong Peninsula are investigated and interviewed.

At the same time, the field investigation method is used to investigate the public sports service activities in the Blue Economic Zone of Shandong Peninsula. 


\section{THE NECESSITY OF CONSTRUCTING THE PUBLIC SPORTS SERVICE SYSTEM IN THE BLUE Economic Zone of Shandong Peninsula}

\section{A. Necessary conditions for the integrated and coordinated development of the Blue Economic Zone of Shandong Peninsula}

In the process of modernization, the Blue Economic Zone of Shandong Peninsula should not only maintain the steady growth of national economy to lay a solid material foundation, but also attach great importance to the construction of spiritual civilization including sports to provide high-quality spiritual products. Sports in modern society are closely related to people's daily life and become an important part of people's modern life. Therefore, the Blue Economic Zone of Shandong Peninsula must speed up the coverage of the whole social area of public sports services, increase the number of public sports products, strengthen the operation efficiency of the public sports service system, and provide sports cultural protection for the functional construction of the Blue Economic Zone of Shandong Peninsula.

\section{B. The demand of economic developed area in Shandong Province to promote the integrated development of public sports services}

The construction of Blue Economic Zone of Shandong Peninsula is the first national development strategy approved in the 12th Five-Year Plan. The integrated development of Blue Economic Zone of Shandong Peninsula is an important strategic decision made by Chinese government. The "one-hour city circle" and "one-city effect" of Blue Economic Zone of Shandong Peninsula describe the future construction. The comprehensive social and economic strength of the cities under the jurisdiction of the Blue Economic Zone of Shandong Peninsula occupies most of the whole development of Shandong Province. In the era of rapid economic development, how to strengthen the core strength of Blue Economic Zone of Shandong Peninsula as an economically developed region to give full play to the radiation function of the economic zone and effectively promote the unified and coordinated development of Blue Economic Zone of Shandong Peninsula and even the whole Shandong Province in terms of ideology, system reform, economic construction, cultural development, social management, etc. is an important issue in the process of economic and social development of Blue Economic Zone of Shandong Peninsula. The core cities in the Blue Economic Zone of Shandong Peninsula not only consider the internal development, but also consider how to influence and drive the development of surrounding cities and regions. The construction of public service plays an important role in the harmonious and stable development of society. Public sports service is an indispensable part of social public service and an important part of urban cultural construction and development of soft power.

\section{Important contents of accelerating the transformation of government functions}

Public sports service is a kind of relaxed and pleasant service activities for citizens, which is easy to make citizens feel the effect of government public services and get citizens' opinions. The effect of the integrated construction of the public sports service system in the Blue Economic Zone of Shandong Peninsula directly reflects the construction of the government public service and the transformation of the government functions. The integrated construction of public sports service system in the Blue Economic Zone of Shandong Peninsula will play an important catalytic role in the transformation of local government functions.

\section{The inevitable requirement of the development of Qilu culture}

Jiaodong culture is an important part of Qilu culture, and sports culture of Jiaodong area is a part of Jiaodong culture. Jiaodong culture has the core characteristics of integration, pragmatism, secularity and innovation, which makes Jiaodong sports culture have strong cultural imprint and strong regional color. The outstanding characteristics of Jiaodong culture, such as the integration of non-excluding foreign culture, the practice of being honest, the secularity of following traditional habits and the innovation of exploring risks, are formed by the long-term labor and life of Jiaodong people in this land. These characteristics of Jiaodong culture provide a continuous power for the economic and cultural construction of Jiaodong area, which transform Jiaodong looks and benefit the people of Jiaodong area. As Qingdao, Yantai, Weihai and other core cities in the Blue Economic Zone of Shandong Peninsula belong to the key cities of Jiaodong Peninsula culture, they play a huge role in promoting the inheritance and development of Jiaodong sports culture. On the one hand, the construction of the integration of the public sports service systems in the Blue Economic Zone of Shandong Peninsula should provide more favorable conditions for the local residents to carry out sports activities, so that Jiaodong sports culture can be well inherited in leisure and happiness. On the other hand, the connotation and extension of Jiaodong sports culture should be enhanced and developed through the organized sports activities that the masses like to hear and see.

\section{E. The urgent demand of sports entering people's life}

With the improvement of people's economic level and living standard, sports have entered thousands of 
households, and become an important part of people's daily life. According to the development law of developed countries, leisure culture including sports will become the main content of social development. The implementation of the integration of public sports service system in the Blue Economic Zone of Shandong Peninsula provides convenient, practical and efficient public sports products and services for the masses.

\section{THE FEASIBILITY OF CONSTRUCTING THE PUBLIC SPORTS SERVICE SYSTEM IN THE BLUE ECONOMIC ZoNe OF SHANDONG PENINSUla}

\section{A. The economic development provides the foundation for the construction of public sports service system in the Blue Economic Zone}

The development of public sports service in the Blue Economic Zone of Shandong Peninsula needs the input of national finance. The investment scale of public sports directly affects the development speed of sports, and also reflects the promotion and influence of public sports service industry on the economic development of the Blue Economic Zone. The structure and proportion of government financial investment in public sports service is not only ideological, conceptual and national sports policy, but also the basis of public sports development in a region.

\section{B. The implementation of policies and regulations provides guarantee for the development of public sports}

Shandong Province has issued the fitness plan corresponding to the national plan. According to the "Opinions of the State Council on the development of sports industry", Shandong Province has successively issued the "Opinions on the development of sports industry in Shandong Province", "Measures for the protection of sports facilities in Shandong Province" and "Measures for the management of sports competitions in Shandong Province". In terms of overall layout and future design, the introduction of policies and regulations on public sports services has defined the goal and set the plan for the development of public sports services in the Blue Economic Zone of Shandong Peninsula, and defined the development direction of sports undertakings in the new period. It has made plans for the implementation of the national fitness plan and the Olympic plan of winning glory, the improvement of the economic policy of sports, the deepening of the reform of the sports system, and the strengthening of the leadership of the sports work, which has opened up a broader space and prospect for the faster development of the sports cause. The development of mass sports is the primary task, which lays the foundation for the development of public sports services.

\section{Problems In The InTEgration OF PUBLIC SPORTS SERVICE SYSTEM IN THE BLUE EConomic Zone of Shandong Peninsula}

\section{A. Imperfect interest coordination mechanism}

There is no effective benefit sharing, integration, protection and compensation mechanism among local governments in the Blue Economic Zone of Shandong Peninsula. Even led by Shandong provincial government, the Office of the Construction of Blue Economic Zone of Shandong Peninsula has been established, which plays a strong coordinating role in the cooperation between the governments of the Blue Economic Zone. Due to incomplete policies and measures, lack of due binding force and credibility, the Blue Economic Zone of Shandong Peninsula has only organized two small-scale fitness activities since its establishment. Although there is a development plan for the Blue Economic Zone of Shandong Peninsula, the cities in the economic zone have been developing on their own for a long time. The various elements of the integration of public sports services can't meet the reasonable allocation, the development of the core cities is not sufficient, the linkage development measures are lacking, and the radiation capacity is poor, which has not met the requirements of the integration of regional development. The government is mainly responsible for the overall development of integration. The government's administrative system directly affects the level of integration.

\section{B. The utilization efficiency of venue resources of public sports service is not high}

The layout of sports facilities is uneven. The layout of different sports venues lacks the rationality, and the allocation of types and functions is not balanced. The residents in non-central city can't get the same public sports services as that in central city, forming the contradiction between the demand for public sports services with expanded interests and the supply of unbalanced public sports services resources.

In the Blue Economic Zone, the utilization efficiency of public sports facilities is not high. The open rate of public sports services in stadiums and gymnasiums is low, and most of them fail to provide public sports places for citizens. There are many colleges and universities in the Blue Economic Zone, but the stadiums and gymnasiums of colleges and universities are not included in the public sports service system.

\section{Lacking the evaluation and feedback mechanism}

Lacking the evaluation and feedback mechanism is the shortcoming of integrated construction of public sports service system in the Blue Economic Zone of Shandong Peninsula. At present, the public sports 
service of the Blue Economic Zone of Shandong Peninsula has not established a series of performance evaluation systems, such as evaluation index, evaluation method, and implementation system and incentive mechanism after evaluation. It is difficult to grasp the real situation of the overall construction and development of the public sports service system of the Blue Economic Zone of Shandong Peninsula. The pertinence of public sports activities is not strong, and it can't guarantee that the public sports resources in the Blue Economic Zone of Shandong Peninsula will play the most effective role.

\section{The guidance of public sports service lacks the efficiency and systematization}

The information network of all cities in the Blue Economic Zone of Shandong Peninsula, the "sports health bus" network of the national fitness monitoring center, the publicity column of each venue, the social sports instructor and other sports service information guidance links operate independently, without forming a unified and mutual communication information system. This affects the systematization of public sports service guidance in the Blue Economic Zone of Shandong Peninsula.

\section{THE CONCEPTION AND MEASURES OF THE INTEGRATED DEVELOPMENT OF THE PUBLIC SPORTS SERVICE SYSTEM IN THE BLUE ECONOMIC Zone OF SHANDONg PENINSUla}

\section{A. Promoting the construction of laws and regulations on public sports service in the Blue Economic Zone of Shandong Peninsula}

It is necessary to strengthen the formulation of laws and policies on public sports services in the Blue Economic Zone of Shandong Peninsula, promote the integration process of laws and policies on public sports services in the Blue Economic Zone, and improve the public sports service system in the Blue Economic Zone of Shandong Peninsula. At the same time, it is required to promote the exchange, cooperation and interactive development of public sports service elements in the economic zone of Shandong Peninsula with the system and rules. All local governments should establish relevant local public sports service policies from the perspective of long-term goals and overall interests, and promote local policies to be unified and open from difference and closure, so as to realize barrier-free flow in the Blue Economic Zone. It is required to build a regional common interest mechanism to promote the coordinated development of public sports services in the Blue Economic Zone of Shandong Peninsula. Also, Shandong Province should actively encourage all regions to make use of their comparative advantages and strengthen cooperation in public sports services, so as to achieve cross-regional complementary and interactive development.

\section{B. Establishing a compound supervision system of public sports service}

The implementation of regional integration means that each city must give up part of its management power and consciously accept the supervision of other cities. The integration of regional public sports services is inseparable from the abandonment of part of the management functions of each city. To participate in the integration of regional public sports services means to sacrifice part of the interests for the healthy and sustainable development of the whole Blue Economic Zone.

The realization of the coordinated development of public sports services in the Blue Economic Zone of Shandong Peninsula is inseparable from the innovation. With the guidance of scientific development concept, it is better to establish the strategic thinking of integrated innovation to solve the problem. At the same time, it is necessary to make the innovation in an all-round way, reconstruct new advantages in development, and realize new leaps in scientific development. Shandong Province should promote the government management theory, improve good service and market competition environment, strengthen social management and public service functions, and create a good administrative environment to promote the coordinated development.

\section{Promoting the reform of management system, integrating the government functions, and meeting the needs of the integrated development of the Blue Economic Zone of Shandong Peninsula}

The most fundamental way to integrate the functions of the government is to eliminate institutional obstacles and carry out institutional innovation. The government function should be weakened from the economic field. It is better to strengthen the establishment and improvement of the market itself, compress the space of government interference by reducing market failure, and realize the transformation of the government function.

First of all, it is required to strengthen the cooperation of relevant government departments, eliminate or narrow the institutional barriers between regions, and expand the public sports service function of the government, especially in the fields of transportation system construction, ecological environment management, independent innovation, and human resources. In terms of regional transportation network cooperation, a fast network system with expressway and intercity rail as the core will be formed, which can follow Rizhao and Qingdao's example to gradually realize the implementation of China T-union in each city of the Blue Economic Zone of Shandong 
Peninsula. With the hardware conditions of "one-hour life circle" in the road network construction, residents in the economic zone will enter the common life circle. Also, it can build the authoritative public sports service information center of Blue Economic Zone of Shandong Peninsula to provide feasible decisionmaking consultation services for the municipal management departments.

Secondly, to realize the integration of public sports services in the Blue Economic Zone of Shandong Peninsula, the fundamental problem is to realize the real transformation of government functions, not only the transformation of administrative organizations and administrative fields. The government should gradually withdraw from the general competitive field, further encourage the development of private enterprises in the competitive field, and expand the proportion of private enterprises. It is necessary to eliminate the short-term behavior of local governments, break the boundaries of household registration, transportation and communication between cities, promote the integration of public sports services of the peninsula, and unify the resource allocation in the peninsula.

\section{Establishing correct performance evaluation standards based on system guarantee}

It is necessary to eliminate the short-sighted behavior of local governments and officials in pursuit of political achievements and change the assessment standard of single index in the past. The new assessment indicators are specific, clear, scientific, normative and feasible. The contents include quantity, speed, quality, social benefit, environmental protection and external influence. It is required to establish a standard assessment method, which should combine the assessment of the superior government with the assessment of the public opinion. Also, it is necessary to establish a reward and punishment mechanism to punish the behaviors of blocking the market and setting obstacles to the flow of elements in the surrounding areas only for local development.

\section{E. Establishing interest coordination organization with multi-agent participation}

It is necessary to strengthen the construction of diversified development of public sports service providers under the guidance of the government. In the process of the integration of public sports services, it is better to define the scope of government functions reasonably, rely on the leading role of the government in public services, increase the financial investment of government, and provide basic conditions for social public sports services. At the same time, it is necessary to promote the social capital investment in the construction of public sports services, rely on the good economic development advantages of the Blue
Economic Zone, introduce market mechanism, drive the social capital investment, improve the mechanism of social capital investment in public sports services, and increase the social participation in public sports activities. Also, it is required to foster a diversified supply system and promote the diversification of production and supply of public sports products. Meanwhile, some functions of public welfare, service and social public sports service of the government can be given down to qualified sports associations and nongovernmental organizations. It can establish an effective cooperative relationship between local governments and non-governmental organizations in the Blue Economic Zone of Shandong Peninsula, so as to make the social and economic benefits complement each other and promote the diversified development of providers.

\section{F. Improving the public network system of sports service in the Blue Economic Zone of Shandong Peninsula}

To build a systematic and efficient integrated network system of public sports services is an important part of improving the integrated construction of public sports services in the Blue Economic Zone of Shandong Peninsula. In the framework of the integration of public sports service system, all levels of the service network departments should have special institutions and personnel responsible for the implementation of public sports services. At the same time, it must establish the coordination mechanism of all departments of public sports service in the Blue Economic Zone of Shandong Peninsula, and introduce more social organizations, professional social groups and amateur clubs to participate in public sports service activities.

Also, it is required to build an integrated information communication and exchange platform for public sports services in the Blue Economic Zone of Shandong Peninsula, timely promulgate public sports services information such as scientific fitness knowledge, regular investigation of the physical condition of citizens, and announcement of various sports activities organized by various cities. Therefore, the public sports service information service network can truly serve the masses of the people in the Blue Economic Zone, and the masses of the people can obtain the required information in time through the public sports information service platform.

Social sports instructor is the most direct guide and manager of public sports activities. All cities in the Blue Economic Zone of Shandong Peninsula should strengthen the construction of the social sports instructor team, formulate the work management regulations and implementation rules of the social sports instructor in the Blue Economic Zone of Shandong Peninsula, and promote various types of 
social sports instructor service systems such as public welfare and professionalism. The personnel, work, knowledge and ability of all social sports instructors in different cities of Blue Economic Zone of Shandong Peninsula shall be managed in a unified way. It is necessary to strengthen the scientific and orderly mobile services of social sports instructors among cities, and form a network service system. Also, it is better to establish a scientific professional training system, carry out regular and irregular on-the-job training for social sports instructors, and update the concept of sports health and professional and technical knowledge of sports fitness in a timely manner, so as to improve the ability of social sports instructors to organize, manage and guide citizens' scientific fitness activities.

\section{CONCLUSION}

Starting with systems and rules, the government should strengthen the construction of laws and regulations, promote the exchange, cooperation and interactive development of public sports service elements in the Blue Economic Zone of Shandong Peninsula.

Also, it is required to promote the management system reform of the economic zone, integrate government functions, and create a sound policy environment.

And it is better to establish a diversified supply system, learn from each other's strengths, and share benefits.

At the same time, the government should also build a diversified and perfect public sports service network system to achieve grid-like services and comprehensively cover all aspects of public sports services.

\section{References}

[1] (United States) Anwa Sha, editor in chief. Public service provision [M]. Beijing: Tsinghua University Press, 2009: 4. (in Chinese)

[2] $\mathrm{Yu}$ Xiaoqian, editor in chief. Theoretical exploration and practical experience of public service performance appraisal [M]. Beijing: Beijing Institute of Technology Press, 2008: 7. (in Chinese)

[3] Chen Wenxin, Zhang Hongzhen, Liu Zhengtan. Concept on integrated development of sports culture in Shandong Peninsula "blue economic zone" [J]. Journal of Shandong Physical Education Institute, 2011 (12): 21-24. (in Chinese)

[4] Sun Leiming. Research on the Development of Sports Integration Against the Background of the Metropolis in the Yangtze River Delta [J]. Journal of Wuhan Institute of Physical Education, 2011 (11): 26-31. (in Chinese)

[5] Yue Hongli. Song Jie. Thoughts on the development of developing urban and rural sports unification [J]. Journal of
Shandong Physical Education Institute, 2013 (5): 11-15. (in Chinese)

[6] Zhang Litian, Construction of Integrated Development Mode for Urban-rural Public Sports Service in Shandong Province [J]. Shandong Sports Science \& Technology, 2013(3): 33-36. (in Chinese) 